\title{
Remote noninvasive allograft rejection monitoring for heart transplant recipients: study protocol for the novel evaluation with home electrocardiogram and remote transmission (NEW HEART) study
}

\author{
Lynn V Doering ${ }^{1 *}$, Kathleen Hickey ${ }^{2}$, David Pickham ${ }^{3}$, Belinda Chen ${ }^{4}$ and Barbara J Drew ${ }^{5}$
}

\begin{abstract}
Background: Acute allograft rejection is a major cause of early mortality in the first year after heart transplantation in adults. Although endomyocardial biopsy (EMB) is not a perfect "gold standard" for a correct diagnosis of acute allograft rejection, it is considered the best available test and thus, is the current standard practice. Unfortunately, $\mathrm{EMB}$ is an invasive and costly procedure that is not without risk. Recent evidence suggests that acute allograft rejection causes delays in ventricular repolarization and thereby increases the cellular action potential duration resulting in a longer QT interval on the electrocardiogram (ECG). No prospective study to date has investigated whether such increases in the QT interval could provide early detection of acute allograft rejection. Therefore, in the Novel Evaluation With Home Electrocardiogram And Remote Transmission (NEW HEART) study, we plan to investigate the potential benefit of daily home QT interval monitoring to predict acute allograft rejection.
\end{abstract}

Methods/design: The NEW HEART study is a prospective, double-blind, multi-center descriptive research study. A sample of 325 adult heart transplant recipients will be recruited within six weeks of transplant from three sites in

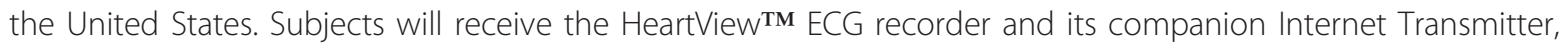
which will transmit the subject's ECG to a Core Laboratory. Subjects will be instructed to record and transmit an ECG recording daily for 6 months. An increase in the QT $T_{C}$ interval from the previous day of at least 25 ms that persists for 3 consecutive days will be considered abnormal. The number and grade of acute allograft rejection episodes, as well as all-cause mortality, will be collected for one year following transplant surgery.

Discussion: This study will provide "real world" prospective data to determine the sensitivity and specificity of QT $C$ as an early non invasive marker of cellular rejection in transplant recipients during the first post-transplant year. A non-invasive indicator of early allograft rejection in heart transplant recipients has the potential to limit the number and severity of rejection episodes by reducing the time and cost of rejection surveillance and by shortening the time to recognition of rejection.

Trial Registration: ClinicalTrials.gov: NCT01365806

Keywords: ECG monitoring, QT interval, Heart transplantation, Allograft rejection

\footnotetext{
* Correspondence: Idoering@sonnet.ucla.edu

'University of California, Los Angeles (UCLA), School of Nursing, 700 Tiverton

Ave., Factor Building 4-266, Los Angeles, Ca 90095, USA

Full list of author information is available at the end of the article
} 


\section{Background}

The prevalence of American adults living with a heart transplant was 20,369 in 2009, the most recent year for which complete data are available [1]. Acute allograft rejection is a major cause of early mortality, a rate that reaches $13 \%$ in the first year after heart transplantation in adults [1,2]. According to the 2011 annual United States data published from the International Society for Heart Lung Transplantation Registry, 26\% of heart transplant recipients have at least one rejection episode within the first year following transplant surgery [2]. Acute rejection remains the most common cause of morbidity and rehospitalization. Jalowiec [3] reported that $64 \%$ of heart transplant recipients were rehospitalized during the first year after transplant surgery (median length of stay, 16 days), and $37 \%$ were rehospitalized more than once. Rejection is also a primary cause of urgent re-transplantation, a situation that is perceived by some to be morally unfair because these patients are allowed a second transplant while others are waiting and often dying before receiving their first transplant. Thus, the financial, physical, and emotional toll associated with acute rejection is significant.

In order to detect the early stages of rejection so that more aggressive and early immunosuppressant therapy can be initiated, frequent biopsies of heart tissue are performed (typically, weekly or every other week in the first three months and then monthly or every other month during the first year). Although endomyocardial biopsy (EMB) is not a perfect "gold standard" for a correct diagnosis of acute allograft rejection, it is considered the best available test and thus, it is the current standard practice. Unfortunately, EMB is an invasive and costly procedure that is not without risk $[4,5]$. If a simple noninvasive biomarker could be identified to detect the early stages of acute rejection, it might be possible to reduce the number of invasive biopsy procedures and to initiate earlier therapy that might prevent death from severe rejection.

Alternatives to invasive EMB monitoring have been the subject of recent study. Most prominently, the use of a commercially available test, the AlloMap, that determines gene-expression profiling of recipient leukocytes, was tested against routine EMB to determine whether adverse events (a composite of allograft dysfunction, death, or retransplantation) differed between patients who received standard EMB monitoring and those who received monitoring by gene-expression profiling [6]. Although the authors concluded that the gene-expression profiling was not inferior to EMB in its association with adverse events, only 6 of 34 rejection episodes in the AlloMap group were identified solely on the basis of the profiling test [6]. Further, the wide confidence intervals for adverse events translated into as much as a $68 \%$ increase in risk with AlloMap monitoring [7]. Most participants were randomized more than one year after transplant, which limits the generalizability of these findings to the higher risk, early ( $<$ one year) post-transplant group that we propose to study.

Other investigators have focused on the electrocardiogram (ECG) as a potential marker of allograft rejection because it is noninvasive and easily measured. Previous studies have investigated the QT interval, an indirect measure of the cellular action potential duration of ventricular myocytes. The QT interval, defined as the interval from the beginning of the QRS complex to the end of the T wave, reflects the time that elapses between the initial fast depolarization of the ventricles and their subsequent repolarization. Recent evidence suggests that acute allograft rejection causes delays in ventricular repolarization and thereby increases the cellular action potential duration resulting in a longer QT interval on the ECG [8-12]. Findings from two studies suggest that the QT interval is linked to acute allograft rejection and three other studies have linked an increased QT interval with mortality (Table 1). However, these studies all have serious limitations. All but one were retrospective analyses. All involved hospital or clinic-acquired ECGs, typically done at baseline seven days following transplant surgery and then annually or at the time of hospitalization for acute severe allograft rejection. Thus, none of the studies could report whether QT interval prolongation was an early sign of rejection or simply the result of severe, irreversible rejection. Another limitation was that all but one study made no mention of investigators being blinded from clinical information about allograft rejection. Thus, it is possible that the researchers making manual measurements of the QT interval were biased by knowing whether the subject did or did not have acute allograft rejection. Despite these limitations, there is evidence that an increase in the QT interval is linked to acute allograft rejection and mortality.

No prospective study to date has investigated whether such increases in the QT interval could provide early detection of acute allograft rejection. In addition, advances in home ECG monitoring have evolved and become less cumbersome and more patient-friendly. Therefore, in the Novel Evaluation With Home Electrocardiogram And Remote Transmission (NEW HEART) study, we plan to take advantage of novel ECG technology to investigate the potential benefit of daily home QT interval monitoring to predict acute allograft rejection following heart transplantation.

\section{Methods/design \\ Design}

The NEW HEART study is a prospective, double-blind, multi-center descriptive research study. The primary 
Table 1 Human Studies on QT Interval Prolongation after Heart Transplantation

\begin{tabular}{|c|c|c|c|c|}
\hline $\begin{array}{c}\# \\
\text { Subjects } \\
\text { Author/Yr } \\
\end{array}$ & Study Design & Major Findings & Study Limitations & $\begin{array}{l}\text { Implications for } \\
\text { NEW HEART Study }\end{array}$ \\
\hline $\begin{array}{l}\mathrm{N}=65 \\
\text { Richartz et } \\
\text { al. } 1998 \\
{[8]}\end{array}$ & $\begin{array}{l}\text { Prospective; Rejection } \\
\text { during in-hospital period }\end{array}$ & $\begin{array}{l}\text { 1. Mean } \mathrm{QT}_{C}=449 \pm 2 \text { ms without } \\
\text { rejection; } 517 \pm 11 \mathrm{~ms} \text { with rejection }(p< \\
0.001) \text { 2. }>10 \% \text { increase in } \mathrm{QT}_{C} \text { predicted } \\
\text { rejection with sensitivity, } 86 \% \text {; specificity, } \\
88 \%\end{array}$ & $\begin{array}{l}\text { 1. Only observed rejection during } \\
\text { hospitalization for transplant surgery } 2 \text {. } \\
\text { Analyzed only } 3 \text { ECGs per subject } 3 \text {. ECG } \\
\text { analyzers not blinded from clinical } \\
\text { information about rejection }\end{array}$ & $\begin{array}{l}\text { An increase in the QT } \\
\text { interval predicts } \\
\text { acute allograft } \\
\text { rejection }\end{array}$ \\
\hline $\begin{array}{l}\mathrm{N}=52 \\
\text { Kolasa et } \\
\text { al. } 2005 \\
{[9]}\end{array}$ & $\begin{array}{l}\text { Retrospective; Long-term } \\
\text { mortality over } 7 \text { yrs }\end{array}$ & $\begin{array}{l}\text { Poorer survival over } 7 \text { yrs in subjects who } \\
\text { had a }>10 \text { ms per year change in their } \\
\text { QT } \text { interval on their annual ECG }\end{array}$ & $\begin{array}{l}\text { 1. Link to rejection not studied } 2 \text {. } \\
\text { Analyzed only one ECG per year }\end{array}$ & $\begin{array}{l}\text { As little as a } 10 \mathrm{~ms} \\
\text { change in the QT } \\
\text { interval is linked to } \\
\text { mortality }\end{array}$ \\
\hline $\begin{array}{l}\mathrm{N}=200 \\
\text { Tenderich } \\
\text { et al. } 2006 \\
{[10]}\end{array}$ & $\begin{array}{l}\text { Retrospective; Rejection } \\
\text { during first } 3 \text { months }\end{array}$ & $\begin{array}{c}\text { > } 25 \text { ms increase in } \mathrm{QT}_{c} \text { interval predicted } \\
\text { acute allograft rejection with sensitivity, } \\
77 \% \text {; specificity, } 96 \% .\end{array}$ & $\begin{array}{l}\text { 1. Only analyzed } 2 \text { ECGs per subject } 2 \text {. } \\
\text { ECG analyzers not blinded from clinical } \\
\text { information about rejection }\end{array}$ & $\begin{array}{c}\text { Increase in QT } \\
\text { interval predicts } \\
\text { acute rejection } \\
\text { during the period of } \\
\text { interest }\end{array}$ \\
\hline $\begin{array}{l}\mathrm{N}=587 \\
\text { Vrtovec et } \\
\text { al. } 2006 \\
{[11]}\end{array}$ & $\begin{array}{l}\text { Retrospective; Long-term } \\
\text { mortality up to } 17 \mathrm{yrs}\end{array}$ & $\begin{array}{l}\text { 1. Patients with } \geq 10 \% \text { increase in } \mathrm{QT}_{C} \\
\text { interval between } 1^{\text {st }} \text { and } 2^{\text {nd }} \text { year post- } \\
\text { transplant had } 6.86 \text { times higher risk of } \\
\text { dying.2. } \geq 10 \% \text { increase in } \mathrm{QT}_{C} \text { was the } \\
\text { only independent predictor of long- term } \\
\text { mortality on multivariate analysis } 3 \text {. Trend } \\
\text { was a decreasing } \mathrm{QT}_{C} \text { over the yrs } \\
\text { suggesting sympathetic reinnervation }\end{array}$ & $\begin{array}{l}\text { 1. Link to rejection not studied } 2 \text {. } \\
\text { Analyzed only one ECG per year }\end{array}$ & $\begin{array}{c}\text { An increase in the QT } \\
\text { interval is linked to } \\
\text { mortality }\end{array}$ \\
\hline $\begin{array}{l}\mathrm{N}=71 \\
\text { Vrtovec et } \\
\text { al. 2008 } \\
{[12]}\end{array}$ & $\begin{array}{l}\text { Retrospective; } 1 \text { - year all- } \\
\text { cause \& SCD mortality in } \\
\text { subjects with severe } \\
\text { acute rejection }\end{array}$ & $\begin{array}{l}\text { 1. QT C was longer in SCD group than in } \\
\text { survivors ( } 475 \pm 57 \text { versus } 437 \pm 36 \mathrm{~ms} ; p \\
=0.02) 2 \text {. Patients who had }>10 \% \\
\text { increase in QT interval during a severe } \\
\text { acute rejection episode were at increased } \\
\text { risk for SCD. }\end{array}$ & $\begin{array}{l}\text { 1. Limited to just patients with severe } \\
\text { rejection; unable to tell whether } \\
\text { increased QT interval could predict } \\
\text { earlier, milder forms of rejection } 2 \text {. } \\
\text { Analyzed just } 2 \text { ECGs per subject (one at } \\
\text { baseline } 7 \text { days after surgery, second at } \\
\text { time of rejection) }\end{array}$ & $\begin{array}{c}\text { An increase in the QT } \\
\text { interval is linked to } \\
\text { mortality }\end{array}$ \\
\hline
\end{tabular}

$\mathrm{ms}=$ millisecond; $\mathrm{SCD}=$ sudden cardiac death; $\mathrm{QTC}=\mathrm{QT}$ interval corrected for heart rate

aims of the NEW HEART study are to: 1) determine whether an increase in the QT interval during the first 6 months following heart transplant is a sensitive and specific biomarker for acute allograft rejection; 2) determine the timing of initial increased QT interval relative to biopsy-diagnosed stages of mild, moderate, and severe allograft rejection.

Secondary aims are to: 1) determine whether an increase in the QT interval during the first 6 months following heart transplant predicts mortality within the first year, and 2) explore additional ECG measurements that might predict acute allograft rejection or death.

\section{Sample}

A sample of 325 adult heart transplant recipients will be recruited from the Columbia University-New York Presbyterian Medical Center (CU-NYP), the University of California, Los Angeles (UCLA), and Cedars Sinai Medical Center (CSMC) in Los Angeles, CA. Respectively, demographic characteristics at these sites are: male (68.9\%, 75.7\%, and 79.7\%); White (53.1\%, 59.1\%, 73.4\%); Black (20.3\%, 9.4\%,12.5\%); Latino (14.5\%, 19.9\%, 9.4\%) and Asian (11.3\%, 10.5\%, 3.1\%) [1]. Inclusion criteria are: 1$) \geq 18$ years of age, 2) first heart transplant surgery within six weeks of their transplant surgery, 3) not enrolled in other research studies that conflict with the study design, 4) clinically stable at time of enrollment (i. e. no clinical symptoms of allograft impairment with ejection fraction $\geq 45 \%$ ).

\section{Instrumentation}

QT interval was selected for monitoring in this study because it is the ECG element most likely to reflect early acute rejection, as previously noted, and because in the setting of early post-transplantation, it is free of neurologically mediated influences. In the first year after transplantation, the cardiac allograft is denervated [13]. A potential major benefit of allograft denervation in the NEW HEART study is that without the confounding influences of heart rate and autonomic nervous system activity, an observed increase in the QT interval is likely to indicate abnormal ventricular repolarization due to another cause, such as acute allograft rejection.

After a thorough search of the available technology, the HeartView ${ }^{\mathrm{TM}}$ ECG Personal Recorder-Transmitter (Aerotel Medical, Israel) was selected. The ECG device records $10 \mathrm{~s}$ of the six limb leads (I, II, III, aVR, aVL, aVF) and two precordial leads (V5 and V6 will be used 
for this study). The HeartView ${ }^{\mathrm{TM}}$ device acquires data at a sampling rate of 500 samples per second which is the standard resolution recommended for diagnostic electrocardiography. The device's reliability and validity for ECG diagnosis are evidenced by approval by the U.S. Food \& Drug Administration that requires the device to meet criteria stipulated by the Association for the Advancement of Medical Instrumentation for electrocardiograph instruments [14].

The HeartView ${ }^{\mathrm{TM}}$ will be used to transmit the subject's ECG to the Core Laboratory at UCSF ("Drew Lab") (Figure 1). Subjects will be given HeartView ${ }^{\mathrm{TM}}$ and Internet Transmitter devices (Aerotel Medical, Israel) for the 6-month monitoring period. Once the patient records his ECG, the HeartView ${ }^{\mathrm{TM}}$ device will automatically seek, find, and upload the ECG by wireless Bluetooth communication to the Internet Transmitter. Then, using mobile phone technology (subscriber identity module [SIM] card), the Internet Transmitter device will automatically seek, find, and send the digital ECG to a UCSF server via wireless General Packet Radio Services (GPRS) internet access. Thus, subjects do not have to dial a telephone to transmit the ECG, nor do they need to have a home computer or even be computer literate. Subjects need only to record their ECG; the rest will be automatic.

\section{Procedures}

Participants will be recruited either while they are in the hospital for transplant surgery, or if that is inconvenient, during their first clinic visit following transplant surgery. After informed consent is obtained, demographic and clinical data will be collected by self-report and by medical record audit. At the time of each EMB, data from the medical record will be abstracted to confirm current medications, serum levels of anti-rejection medications, clinical data regarding EMB results, and other clinical data reflecting myocardial performance consistent with rejection status. Only one anti-rejection medication (tacrolimus) is associated with an increased QT interval. If a patient is on chronic tacrolimus therapy without a change in dosage, it should not interfere with the daily ECG monitoring measurement because we will be comparing each patient with him/herself and noting any change from the previous day's QT interval. However, we will track initiation or change in any QT-prolonging drug. On their website, the Arizona Center for Education and Research on Therapeutics [15] maintains a comprehensive list of QT- prolonging drugs that we have incorporated into the medications section of our electronic database system. Further, on a quarterly basis, we will continue to reference this website for new drugs as they come to market and update our data capture to include those associated with QT-prolongation.

The other drug class that patients may be taking is 3Hydroxy-3-Methyl-Glutaryl Coenzyme A Reductase inhibitors (i.e., statins) which are known to shorten the QT interval. Thus, we will also monitor statin therapy. To insure patient safety, we will notify patients' transplant cardiologists within $48 \mathrm{~h}$ of the detection of any QTc interval exceeding the population 99th percentile for adult males (> $470 \mathrm{~ms}$ ) or females (> $480 \mathrm{~ms}$ ) [16].

At the time of informed consent and enrollment, subjects will receive the HeartView ${ }^{\mathrm{TM}}$ recorder and its

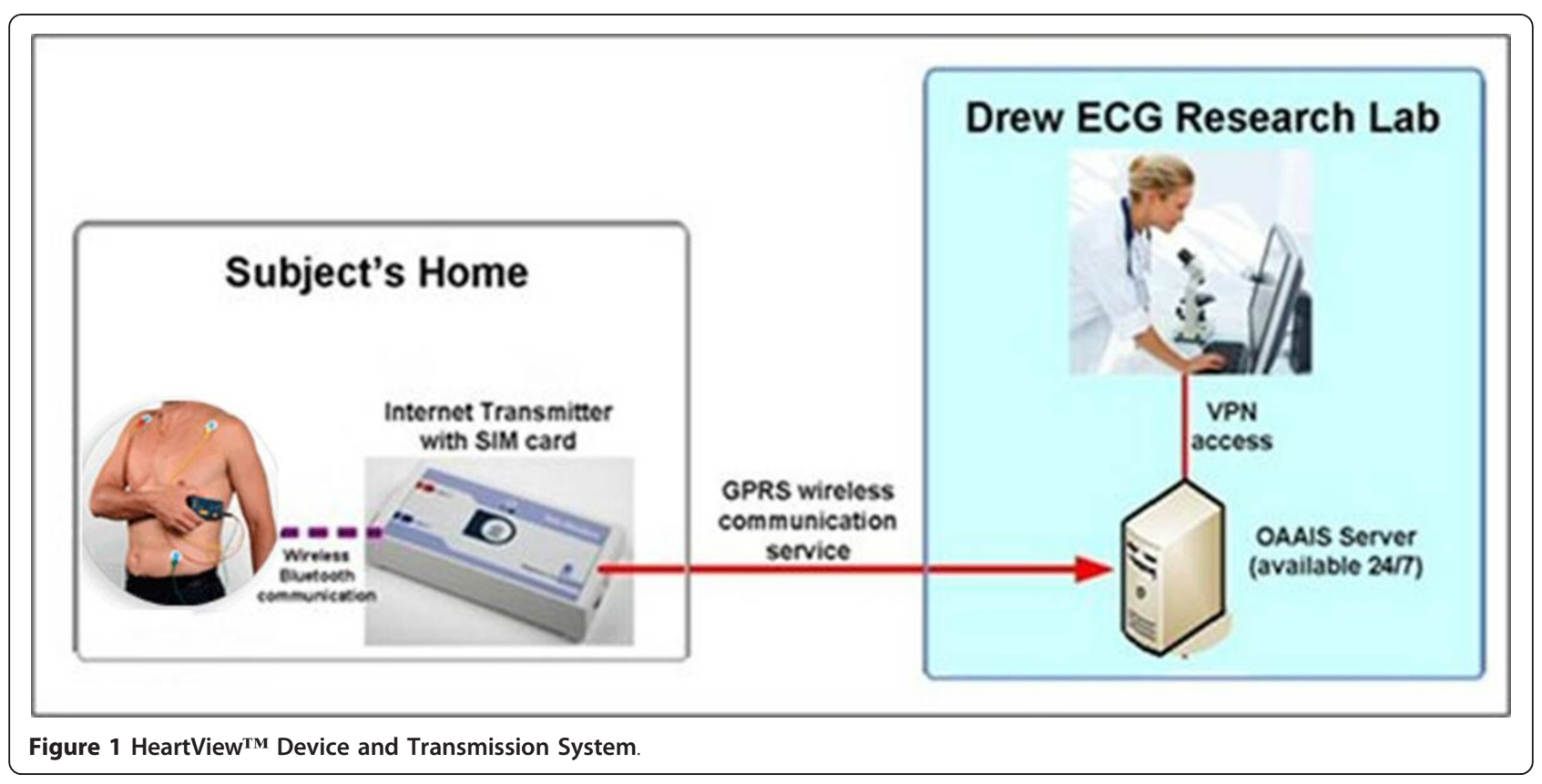


companion Internet Transmitter, which will transmit the subject's ECG as described earlier. Subjects will be asked to record a 10-s 8-lead ECG daily for 6 months.

Participants and their caregivers, if available, will be instructed in the use of the HeartView device using a standardized training booklet. Each enrollee will be given the opportunity to practice transmission and will receive feedback, if needed, prior to the beginning of daily recordings. Daily recordings will be monitored by study personnel to insure quality of transmissions.

Participants will be instructed to make and upload ECG recordings at any time of day that is convenient for them, although they will be urged to select a consistent time to promote adherence to recording. Across participants, a standard recording time is not required because in the early post transplant period complete allograft denervation results in failure of parasympathetic or sympathetic nerves to influence heart rate. In normal individuals at rest, parasympathetic influences via the vagus nerve predominate resulting in a resting heart rate of $60-90$ beats/min in adults. However, without such parasympathetic influence on the allograft, transplant recipients experience a permanent tachycardia $(99 \pm 12$ beats $/ \mathrm{min}$ ) and exhibit little heart rate variability over a $24 \mathrm{~h}$ period [17]. For the current study, this means that subjects will be able to record their daily ECGs at any time without the confounding influence of 24-h variability on ECG intervals. However, participants will be instructed to wait for at least ten minutes after exercising before recording an ECG. This is necessary because allograft beta receptors are functional early after transplant [17] and respond to increases in circulating catecholamines, such as that elicited by exercise. This post-transplant response to exercise is less immediate than in normal individuals and after cessation of exercise, peak heart rate also recedes at a slower pace, over about a 10-min period [17].

\section{Analysis of ECG monitoring data}

The ECG will be sent to a large server hosted by the UCSF Office of Academic and Administrative Information Systems (OAAIS). The server is a secure, highly redundant data center with $24 / 7$ availability due to back-up generators that protect against power outages. The system provides nightly data backup. Investigators in the Drew Lab will access the ECG data by logging on with a username and password via a Virtual Private Network (VPN), which encapsulates data transfers between networked devices not on the same private network and keeps the transferred data private from other devices. Investigators who analyze the daily ECG data will be blinded from all information regarding the subject's clinical status and biopsy results. In addition, pathologists who grade the biopsies and clinicians who provide medical care in the transplant clinics will be blinded from the QT interval monitoring data.

QT and RR intervals will be made in a computerassisted manner. The Aerotel measurement software provides a zooming feature to enlarge ECG waveforms for better visualization. In addition, electronic calipers are provided so that the researcher will select the appropriate waveform onset and offset points and the computer software will provide the interval value in milliseconds (ms). The QT interval will be measured from the onset of the QRS waveform to the end of the $\mathrm{T}$ waveThe end of the $\mathrm{T}$ wave will be defined as the intersection of a tangent to the steepest slope of the last limb of the $\mathrm{T}$ wave and the baseline (Figure 2) [18]. A standardized correction to account for the effect of HR will be applied $\left(\mathrm{QT}_{\mathrm{C}}\right)$. An increase in the $\mathrm{QT}_{\mathrm{C}}$ interval from the previous day of at least $25 \mathrm{~ms}$ that persists for 3 consecutive days will be considered abnormal [10].

To explore the potential diagnostic and prognostic value of additional ECG measurements, the following variables will also be measured on the daily ECG recordings: cardiac rhythm, heart rate, $\mathrm{P}$ wave and QRS duration, PR interval, QRS amplitude, and the interval from the peak of the $T$ wave to the end of the $T$ wave [19]. A prolonged $T_{\text {PEAK }}-T_{\text {END }}$ interval is thought to represent heterogeneity of ventricular repolarization across the 3 layers of the myocardial wall [20] and has been associated with risk for sudden cardiac death from torsades de pointes [21].

\section{Diagnosis of acute allograft rejection}

Rates of acute allograft rejection have varied, but the most recent rates of rejection in the first 6 months after transplant are reported to be 25 to $35 \%$ [2]. The diagnosis of acute allograft rejection is made by an EMB which will be performed in the hospital cardiac catheterization laboratory at each site. Generally, 3-6 biopsy specimens of the right ventricular endocardium are taken to minimize false negative tests. Each site will follow its own acute rejection surveillance protocol. In general, these protocols require weekly or biweekly EMBs during the first two to three post-transplant months. After that time, biopsies are performed less frequently, based on clinical judgment and risk of rejection. At each site, EMBs will be graded by clinical pathologists experienced with the heart transplant population and using the International Society of Heart and Lung Transplantation standards for acute rejection. Although early reports indicated inter-operator variability in the interpretation of EMB results [22], the use of the standardized grading system has improved the reliability and validity of the measurement. Current variability in interpretation of biopsy results occurs mainly in the diagnosis of Grade 2 rejection by local pathologists which may be 


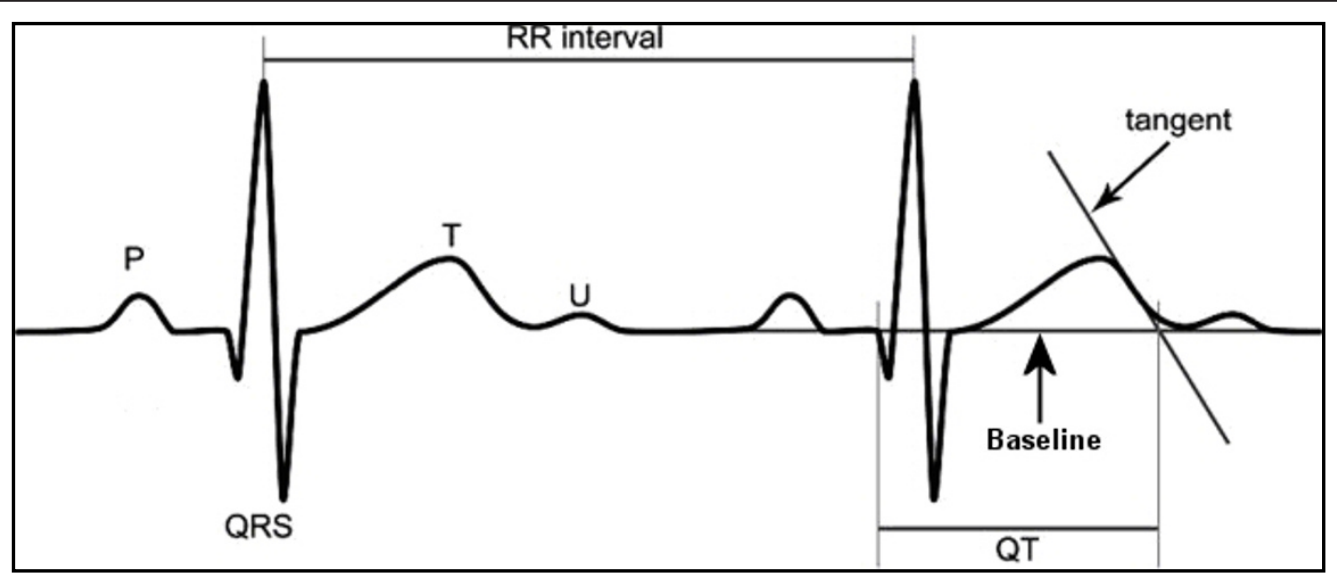

Figure 2 Measurement of QT Interval. A tangent is drawn to the steepest slope of the last limb of the T wave; the end of the T wave is the intersection of this tangent with the baseline.

misinterpreted in the presence of endocardial infiltrates called Quilty lesions $[23,24]$. To control for potential variability, we will monitor and record clinical and hemodynamic indicators of myocardial performance, which are obtained at the time of each biopsy or at regular clinical assessments, to support the biopsy interpretation, particularly regarding Grade 2 rejection. Such a multi-factorial approach to identification of rejection has been recommended [24].

\section{Follow-up and end-points}

The number and grade of acute allograft rejection episodes will be collected for a period of one year following transplant surgery. Data on all-cause mortality within the first year will be collected. Because all transplant centers are required to report their data to the transplant registry, we anticipate no loss to follow-up or missing data regarding rejection or death.

\section{Data management}

To insure accuracy of data collection, all sites will use a secure web-based data capture site, Research Electronic Data Capture (REDCap) [25], which is sponsored by a consortium of 118 research institutions. REDCap offers a stream-lined process for rapidly building a database, an interface for data collection and validation, and automated export procedures for download to statistical packages. As part of our pilot study, we developed, initiated, and refined a REDCap database which is ready for use in the proposed study.

\section{Statistical analysis}

Using the variable definitions in Table 2, a logistic regression analysis will be performed with the independent variable being presence/absence of the ECG criteria $\left(\Delta \mathrm{QT}_{\mathrm{C}} \geq+25 \mathrm{~ms} \times 3\right.$ days [10]) and the dependent variable being presence/absence of acute allograft rejection. Odds ratios and confidence intervals will be reported as well as the universal proportions used to determine the value of new diagnostic criteria (sensitivity, specificity, positive/negative predictive value, and predictive accuracy, Table 3).

Descriptive statistics (means $\pm \mathrm{SD}$ ) will be used to describe the average time period between the development of the ECG criterion and biopsy evidence of rejection. In addition, we will report the proportion of subjects who develop the ECG criterion $(\geq+25 \mathrm{~ms}$ increase in QT interval from previous day lasting 3 consecutive days [10]) before, during, or after the stages of mild, moderate, and severe rejection.

The Kaplan-Meier method with the log-rank test will be used to estimate survival curves over one year and to compare all-cause mortality in patients who are positive or negative for the $\mathrm{QT}_{\mathrm{C}}$ criterion. Cox Proportional Hazard modeling will be used to control for baseline differences between groups and for tacrolimus use.

Logistic regression will be used with the dependent variables of rejection (yes/no) and all- cause mortality (yes/no). In both regressions, tacrolimus dosage (with " 0 " entered if the patient is not receiving tacrolimus) will be included as a covariate in the model. If any of the explorative variables are statistically significant, a multiple logistic regression model will be used including the ECG criterion of interest to determine whether additional ECG criteria are independent predictors of rejection and death.

\section{Ethics approval}

Institutional Review Board (IRB) approvals have been obtained at all participating sites. Although this is not a randomized clinical trial, we are implementing an external Data Safety Monitoring Board (DSMB), consisting of 
Table 2 Variable definitions for statistical analysis

\begin{tabular}{|c|c|c|}
\hline Variable & Definition & Type of Variable \\
\hline$\Delta \mathrm{QT}_{\mathrm{C}}$ & $\geq+25$ ms increase in $\mathrm{QT}_{\mathrm{C}}$ interval from previous day lasting 3 consecutive days [10] & $\begin{array}{l}\text { Continuous (expected range, } 10-100 \\
\text { ms) }\end{array}$ \\
\hline $\begin{array}{l}\text { Acute allograft } \\
\text { rejection } \\
\end{array}$ & $\begin{array}{c}\text { EMB category } 1 \mathrm{R} \text { or } 2 \mathrm{R} \text { or } 3 \mathrm{R} \text { with confirmation by } \\
\text { treating physician }\end{array}$ & $\begin{array}{c}\text { Categorical; dichotomous (yes/no) No } \\
=0 ; \text { Yes }=1 \mathrm{R} \text { or } 2 \mathrm{R} \text { or } 3 \mathrm{R}\end{array}$ \\
\hline $\begin{array}{l}\text { Days to } \\
\text { rejection }\end{array}$ & $\begin{array}{l}\text { Number of days from first positive ECG criterion to mild, moderate, or severe rejection } \\
\text { diagnosis. If the ECG criterion follows rejection, a negative \# of days } \\
\text { will be reported. }\end{array}$ & $\begin{array}{l}\text { Continuous (expected range }-365 \text { to } \\
\qquad+365)\end{array}$ \\
\hline $\begin{array}{l}\text { Acute } \\
\text { rejection } \\
\text { severity }\end{array}$ & EMB category: 1R (mild), 2R (moderate), 3R (severe) & Categorical \\
\hline $\begin{array}{l}\text { Cardiac } \\
\text { rhythm }\end{array}$ & Sinus rhythm, atrial fibrillation, atrial flutter, junctional rhythm & Categorical \\
\hline Heart rate & Heart rate per minute calculated from $30 \mathrm{~s}$ rhythm strip & Continuous (expected range, 60-120) \\
\hline $\begin{array}{l}\text { P wave } \\
\text { duration }\end{array}$ & Interval from beginning to end of $\mathrm{P}$ wave in ms (measure of intra-atrial conduction delay) & $\begin{array}{l}\text { Continuous (expected range, } 70-126 \\
\text { ms) }\end{array}$ \\
\hline QRS duration & Interval from beginning to end of the QRS waveform & $\begin{array}{l}\text { Continuous (expected range, } 72-160 \\
\text { ms) }\end{array}$ \\
\hline PR interval & $\begin{array}{l}\text { Interval from the beginning of the P wave to the beginning of the QRS complex measured } \\
\text { in ms. PR interval }>200 \mathrm{~ms} \text { indicates an abnormal delay of conduction }\left(1^{\text {st }} \text { degree AV }\right. \\
\text { block). }\end{array}$ & $\begin{array}{l}\text { Continuous (expected range, } 112-240 \\
\text { ms) }\end{array}$ \\
\hline $\begin{array}{c}\text { QRS } \\
\text { amplitude }\end{array}$ & Height of QRS waveform in $\mu \mathrm{V}$ & $\begin{array}{c}\text { Continuous (expected range, 500-1000 } \\
\mu \mathrm{V}\end{array}$ \\
\hline$T_{P E A K}-T_{E N D}$ & $\begin{array}{c}\text { Interval from the peak of the } T \text { wave (or nadir in inverted } T \text { waves) to the end of the } T \\
\text { wave in ms. Prolonged T TEAK }-T_{\text {END }} \text { indicates heterogeneity of repolarization and risk for } \\
\text { arrhythmia }\end{array}$ & $\begin{array}{c}\text { Continuous (expected range, } 112-240 \\
\text { ms) }\end{array}$ \\
\hline
\end{tabular}

a clinical expert, a statistician, and an ethicist. The DSMB will be charged with providing guidance regarding subject recruitment and retention, issues related to implementation of the study protocol, any adverse events, and any complaints or problems emanating from participants. The DSMB will meet at least annually to review study progress and make recommendations to the investigators.

\section{Discussion}

An increased $\mathrm{QT}_{\mathrm{C}}$ interval in heart transplant recipients is linked to acute allograft rejection and death. Normal variation in $\mathrm{QT}_{\mathrm{C}}$ intervals over $24 \mathrm{~h}$ due to changing autonomic nervous system tone does not occur in heart transplant recipients because transplant surgery causes denervation of the allograft. Thus, an increase in $\mathrm{QT}_{\mathrm{C}}$ is likely to indicate cellular dysfunction that occurs with acute rejection. Prior research is inadequate to determine whether monitoring the QT interval would be valuable to detect acute allograft rejection because the studies have been retrospective and involved just a few ECGs recorded periodically and analyzed by investigators who were not blinded from information about rejection episodes.

The NEW HEART study focuses on the potential for future reduction in the number of EMBs which transplant recipients must endure in the first year following transplantation. While EMB remains the gold standard for detection of cellular rejection in heart transplant recipients, it is costly, inconvenient, and not without risk $[4,5,26]$. Increased $\mathrm{QT}_{\mathrm{C}}$ has been linked to acute allograft rejection, but has not been systematically evaluated in prospective studies. This investigation will provide "real world" prospective data to determine the

Table 3 Definitions of Universal Proportions

\begin{tabular}{cl}
\hline Criterion & Definition \\
\hline Sensitivity & Proportion of those with acute rejection who are positive for the ECG criterion \\
\hline Specificity & Proportion of those without rejection who are negative for the ECG criterion \\
\hline Positive Predictive Value & Proportion of patients with positive ECG criterion who have rejection \\
\hline Negative Predictive Value & Proportion of patients with negative ECG criterion who do not have rejection \\
\hline Predictive Accuracy & \#true positives \pm true negatives by the ECG criterion \\
\cline { 2 - 2 } & Total \# of patients enrolled in the study $\times 100$ \\
\hline
\end{tabular}


sensitivity and specificity of $\mathrm{QT}_{\mathrm{C}}$ as an early non invasive marker of cellular rejection in transplant recipients during the first post-transplant year.

A non-invasive indicator of early allograft rejection in heart transplant recipients has the potential to limit the number and severity of rejection episodes by reducing the time and cost of rejection surveillance and by shortening the time to recognition of rejection. Additionally, achievement of the aims of the current study may identify other ECG parameters relevant for non-invasive allograft rejection monitoring and may provide support for a randomized controlled trial to determine the efficacy and cost-effectiveness of this type of noninvasive ECG monitoring compared with standard EMB surveillance.

\section{Abbreviations}

EMB: Endomyocardial Biopsy; ECG: Electrocardiogram; NEW HEART: Novel Evaluation with Home Electrocardiogram And Remote Transmission: CHARM Computerized Heart Allograft Recipient Monitoring; UCSF: University of California - San Francisco; SIM: Subscriber Identity Module; GPRS: General Packet Radio Services; CU-NYP: Columbia University-New York Presbyterian Medical Center; UCLA: University of California: Los Angeles (UCLA); CSMC: Cedars Sinai Medical Center; OAAIS: Office of Academic and Administrative Information Systems (OAAIS); VPN: Virtual Private Network; REDCap: Research Electronic Data Capture; DSMB: Data Safety Monitoring Board; QTc: QT interval corrected for heart rate.

\section{Acknowledgements}

This study is supported by a grant from the National Institute of Health/ National Institute of Nursing Research (R01NR012003). The authors would also like to acknowledge the support of Drs. Mario Deng, Jon Kobashigawa, and Donna Mancini.

\section{Author details}

${ }^{1}$ University of California, Los Angeles (UCLA), School of Nursing, 700 Tiverton Ave., Factor Building 4-266, Los Angeles, Ca 90095, USA. ${ }^{2}$ Columbia University, School of Nursing, 630 West 168th Street, New York, NY 10032 , USA. ${ }^{3}$ University of California, San Francisco (UCSF), 2 Koret Way, N611H, San Francisco, CA 94143-0610, USA. ${ }^{4}$ University of California, Los Angeles (UCLA), School of Nursing 700 Tiverton Ave. Factor Building 4-266, Los Angeles, Ca 90095, USA. 5 University of California, San Francisco (UCSF), 2 Koret Way, N611H, San Francisco, CA 94143-0610, USA.

\section{Authors' contributions}

BD and LD developed the study concept, aims, and methods. BD, LD, and $\mathrm{KH}$ co-wrote the study protocol. All authors are implementing the study protocol. $\mathrm{LD}, \mathrm{KH}$, and $\mathrm{BC}$ are overseeing enrollment and collection of clinical data. BD and DP are overseeing electronic ECG data collection and analysis. $B D, L D$ and $K H$ will oversee final data analysis. LD and BC drafted the study manuscript and all authors contributed to, read and approved the final manuscript.

\section{Competing interests}

The authors declare that they have no competing interests.

Received: 11 January 2012 Accepted: 2 March 2012

Published: 2 March 2012

\section{References}

1. The Organ Procurement and Transplantation Network. [http://optn. transplant.hrsa.gov/data/].

2. Stehlik J, Edwards LB, Kucheryavaya AY, Benden C, Christie JD, Dobbels F, Kirk R, Rahmel AO, Hertz Ml: The Registry of the International Society for Heart and Lung Transplantation: Twenty-eighth adult heart transplant report - 2011. The Journal of Heart and Lung Transplantation 2011, 30(10):1078-1094.

3. Jalowiec A, Grady KL, White-Williams C: Predictors of rehospitalization time during the first year after heart transplant. Heart Lung 2008, 37(5):344-355

4. Fiorelli Al, Coelho GHB, Oliveira JL Jr, Aiello VD, Benvenuti LA, Santos A, Chi A, Tallans A, Igushi ML, Bacal F, et al: Endomyocardial Biopsy as Risk Factor in the Development of Tricuspid Insufficiency After Heart Transplantation. Transplant Proc 2009, 41(3):935-937.

5. Hamour IM, Burke MM, Bell AD, Panicker MG, Banerjee R, Banner NR: Limited Utility of Endomyocardial Biopsy in the First Year after Heart Transplantation. Transplantation 2008, 85(7):969-974.

6. Pham MX, Teuteberg JJ, Kfoury AG, Starling RC, Deng MC, Cappola TP, Kao A, Anderson AS, Cotts WG, Ewald GA, et al: Gene-Expression Profiling for Rejection Surveillance after Cardiac Transplantation. N Engl J Med 2010, 362(20):1890-1900.

7. Jarcho JA: Fear of Rejection - Monitoring the Heart-Transplant Recipient. N Engl J Med 2010, 362(20):1932-1933.

8. Richartz BM, Radovancevic B, Bologna MT, Frazier OH: Usefulness of the QTc interval in predicting acute allograft rejection. Thorac Cardiovasc Surg 1998, 46(4):217-221.

9. Kolasa MW, Lee JC, Atwood JE, Marcus RR, Eckart RE: Relation of QTc duration heterogeneity to mortality following orthotopic heart transplantation. Am J Cardiol 2005, 95(3):431-432.

10. Tenderich G, Jahanyar J, Zittermann A, Schleithoff SS, Wlost S, Korfer R: Predictive value of ECG changes for acute cardiac rejections in heart transplant recipients. Med Klin (Munich) 2006, 101(2):99-106.

11. Vrtovec B, Radovancevic R, Thomas CD, Yazdabakhsh AP, Smart FW, Radovancevic B: Prognostic value of the QTc interval after cardiac transplantation. J Heart Lung Transplant 2006, 25(1):29-35.

12. Vrtovec B, Haddad F, Tsai V, Al-Ahmad A, Cause T, Pham M, Fisher P, Fearon W, Valentine H, Hunt S: QT Interval Prolongation during Severe Acute Rejection is Predictive of Sudden Cardiac Death in Heart Transplant Recipients. Circulation 2008, 118(18):S801-S801.

13. Überfuhr P, Frey AW, Ziegler S, Reichart B, Schwaiger M: Sympathetic reinnervation of sinus node and left ventricle after heart transplantation in humans: regional differences assessed by heart rate variability and positron emission tomography. The Journal of Heart and Lung Transplantation 2000, 19(4):317-323.

14. Diagnostic electrocardiographic devices. American National Standard. second edition. Arlington: Association for the Advancement of Medical Instrumentation; 2001, Edited by ANSI/AAMI, vol. EC11-1991 (R).

15. ARIZONA CERT Center for Education and Research on Therapeutics.

16. Drew BJ, Ackerman MJ, Funk M, Gibler WB, Kligfield P, Menon V, Philippides GJ, Roden DM, Zareba W, The American Heart Association Acute Cardiac Care Committee of the Council on Clinical Cardiology tCoCN, et al: Prevention of Torsade de Pointes in Hospital Settings: A Scientific Statement From the American Heart Association and the American College of Cardiology Foundation. Circulation 2010, 121(8):1047-1060.

17. Babuty D, Aupart M, Cosnay P, Sirinelli A, Rouchet S, Marchand M, Fauchier JP: Electrocardiographic and electrophysiologic properties of cardiac allografts. J Cardiovasc Electrophysiol 1994, 5(12):1053-1063.

18. Postema PG, De Jong JS, Van der Bilt IA, Wilde AA: Accurate electrocardiographic assessment of the QT interval: teach the tangent. Hear Rhythm 2008, 5(7):1015-1018.

19. Topilski I, Rogowski O, Rosso R, Justo D, Copperman Y, Glikson M, Belhassen B, Hochenberg M, Viskin S: The morphology of the QT interval predicts torsade de pointes during acquired bradyarrhythmias. J Am Coll Cardiol 2007, 49(3):320-328.

20. Antzelevitch C, Shimizu W: Cellular mechanisms underlying the long QT syndrome. Curr Opin Cardiol 2002, 17(1):43-51.

21. Akar FG, Yan GX, Antzelevitch C, Rosenbaum DS: Unique topographical distribution of $M$ cells underlies reentrant mechanism of torsade de pointes in the long-QT syndrome. Circulation 2002, 105(10):1247-1253.

22. Winters GL, McManus BM: Consistencies and controversies in the application of the International Society for Heart and Lung Transplantation working formulation for heart transplant biopsy specimens. Rapamycin Cardiac Rejection Treatment Trial Pathologists J Heart Lung Transplant 1996, 15(7):728-735.

23. Yang HM, Lai CK, Gjertson DW, Baruch-Oren T, Ra SH, Watts W, Wallace WD Shintaku P, Kobashigawa JA, Fishbein MC: Has the 2004 revision of the 
International Society of Heart and Lung Transplantation grading system improved the reproducibility of the diagnosis and grading of cardiac transplant rejection? Cardiovasc Pathol 2009, 18(4):198-204.

24. Marboe CC, Billingham M, Eisen H, Deng MC, Baron H, Mehra M, Hunt S, Wohlgemuth J, Mahmood I, Prentice J, et al: Nodular endocardial infiltrates (Quilty lesions) cause significant variability in diagnosis of ISHLT Grade 2 and 3A rejection in cardiac allograft recipients. J Heart Lung Transplant 2005, 24(7 Suppl):S219-S226.

25. REDCap. [http://www. project-redcap.org/]

26. Chen JM: "Take Another Little Piece of My Heart Now": Should Endomyocardial Biopsy Remain the Gold Standard? [Editorial]. Transplantation 2008, 85(7):934.

\section{Pre-publication history}

The pre-publication history for this paper can be accessed here: http://www.biomedcentral.com/1471-2261/12/14/prepub

doi:10.1186/1471-2261-12-14

Cite this article as: Doering et al:: Remote noninvasive allograft rejection monitoring for heart transplant recipients: study protocol for the novel evaluation with home electrocardiogram and remote transmission (NEW HEART) study. BMC Cardiovascular Disorders 2012 12:14.

\section{Submit your next manuscript to BioMed Central} and take full advantage of:

- Convenient online submission

- Thorough peer review

- No space constraints or color figure charges

- Immediate publication on acceptance

- Inclusion in PubMed, CAS, Scopus and Google Scholar

- Research which is freely available for redistribution

Submit your manuscript at www.biomedcentral.com/submit 